\title{
Attenuation or absence of circadian and seasonal rhythms of acute myocardial infarction
}

Jeremy W Sayer, Paul Wilkinson, Kulasegaram Ranjadayalan, Saumitra Ray,
Bradley Marchant, Adam D Timmis

\begin{abstract}
Objectives-To examine the circadian, seasonal, and weekly rhythms of acute myocardial infarction, and to identify subgroups in whom the rhythms are attenuated or absent to provide further information about the mechanisms of the rhythms and the processes responsible for triggering plaque events.

Design and setting-Prospective, observational study in a general hospital.

Patients and methods-1225 consecutive patients admitted to a coronary care unit with acute myocardial infarction were studied. Admission rates were calculated according to the hour of the day (circadian rhythm), day of the week (weekly rhythm), and month of year (seasonal rhythm). The data were analysed for variations within the whole group and within subgroups.
\end{abstract}

Results-A weekly rhythm of acute myocardial infarction could not be demonstrated but there was a trend towards higher admission rates at the beginning of the week. However, the time of onset of symptoms showed significant circadian variation for the group as a whole, peaking in the morning $(\mathbf{P}=$ 0.006), against an otherwise fairly constant background rate. Subgroup analysis showed complete absence of the circadian rhythm in patients who were diabetic, South Asian, or taking $\beta$ blockers or aspirin on admission. Significant seasonal variation in admission rates was also demonstrated for the group as a whole with a winter peak and a summer trough $(P=0.009)$. Again, no seasonal rhythm could be demonstrated in patients who were diabetic, South Asian, or taking $\beta$ blockers or aspirin on admission.

Conclusions-The absence of circadian and seasonal rhythms of acute myocardial infarction in almost identical subgroups suggests that common mechanisms are involved in driving these rhythms. The autonomic nervous system is a likely candidate because the rhythms were absent in patients taking $\beta$ blockers as well as in patients in whom derangement of autonomic function commonly occurs.

(Heart 1997;77:325-329)

Keywords: circadian rhythm; seasonal rhythm; acute myocardial infarction; autonomic nervous system
Coronary syndromes often show circadian variability with a peak in the second quarter of the day. This applies to acute myocardial infarction, ${ }^{1-6}$ sudden death, ${ }^{7}$ stable angina, ${ }^{8}$ and silent ischaemia. ${ }^{9} 10 \mathrm{We}$ have previously confirmed a circadian rhythm for acute myocardial infarction within our own patient population and have also demonstrated a seasonal rhythm determined largely by environmental temperature. ${ }^{11}$ In addition to these circadian and seasonal rhythms, the onset of acute myocardial infarction may be influenced by the day of the week, a number of investigators reporting a peak on Monday mornings. ${ }^{12-15}$

It is now clear that the circadian rhythm of acute myocardial infarction may be attenuated or absent in certain subgroups, particularly patients who are diabetic or taking $\beta$ blockers. ${ }^{461617}$ Modified circadian rhythms have also been reported in women and smokers. ${ }^{4}$ These findings have prompted speculation about the mechanisms that may be responsible for the circadian rhythm of acute myocardial infarction and have contributed to current concepts of the provocation of plaque events. Less is known about seasonal rhythm, and it is not known whether it shares common mechanisms with the diurnal rhythm or operates independently. The question is important because if the mechanisms that drive these rhythms can be identified, it will not only increase our understanding of the pathogenesis of infarction but may also permit application of treatment to protect patients during periods of heightened risk.

The present study examined the circadian, seasonal, and weekly rhythms of acute myocardial infarction. We tried to identify

Table 1 Patient characteristics. Figures in parentheses indicate the number of patients for whom data were available

\begin{tabular}{ll}
\hline & Number (\%) \\
\hline Age (1225) & \\
<65 years & $695(57)$ \\
₹65 years & $325(43)$ \\
Sex (1225) & \\
$\quad$ Men & $900(74)$ \\
$\quad$ Women & $325(26)$ \\
Smoking (1201) & \\
$\quad$ Non-smoker & $566(47)$ \\
$\quad$ Current smoker & $635(53)$ \\
Diabetes (1222) & $252(21)$ \\
Racial group (1225) & \\
$\quad$ White & $916(74)$ \\
South Asian & $284(23)$ \\
Other & $25(3)$ \\
Admitted on $\beta$ blockers (1125) & $166(15)$ \\
Admitted on aspirin (1129) & $146(13)$ \\
Previous myocardial infarction (1223) & $309(25)$ \\
\hline
\end{tabular}

\author{
Correspondence to: \\ Dr A D Timmis, London \\ Chest Hospital, Bonner \\ Road, London E2
United Kingdom. \\ Accepted for publication \\ 27 November 1996 \\ London, United \\ Kingdom \\ K Ranjadayalan
}




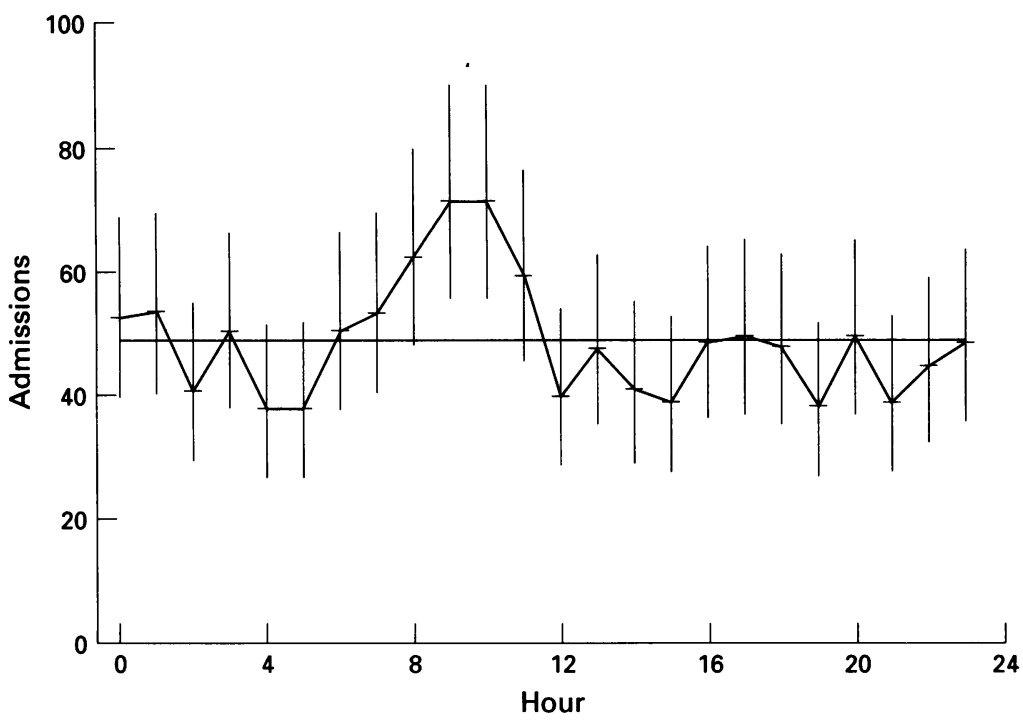

Figure 1 Admission rates by hour of day for 1182 patients. Test for heterogeneity, $\chi^{2}=$ 43.5 on 23 degrees of freedom, $P=0.006$. Error bars are $95 \%$ confidence intervals.
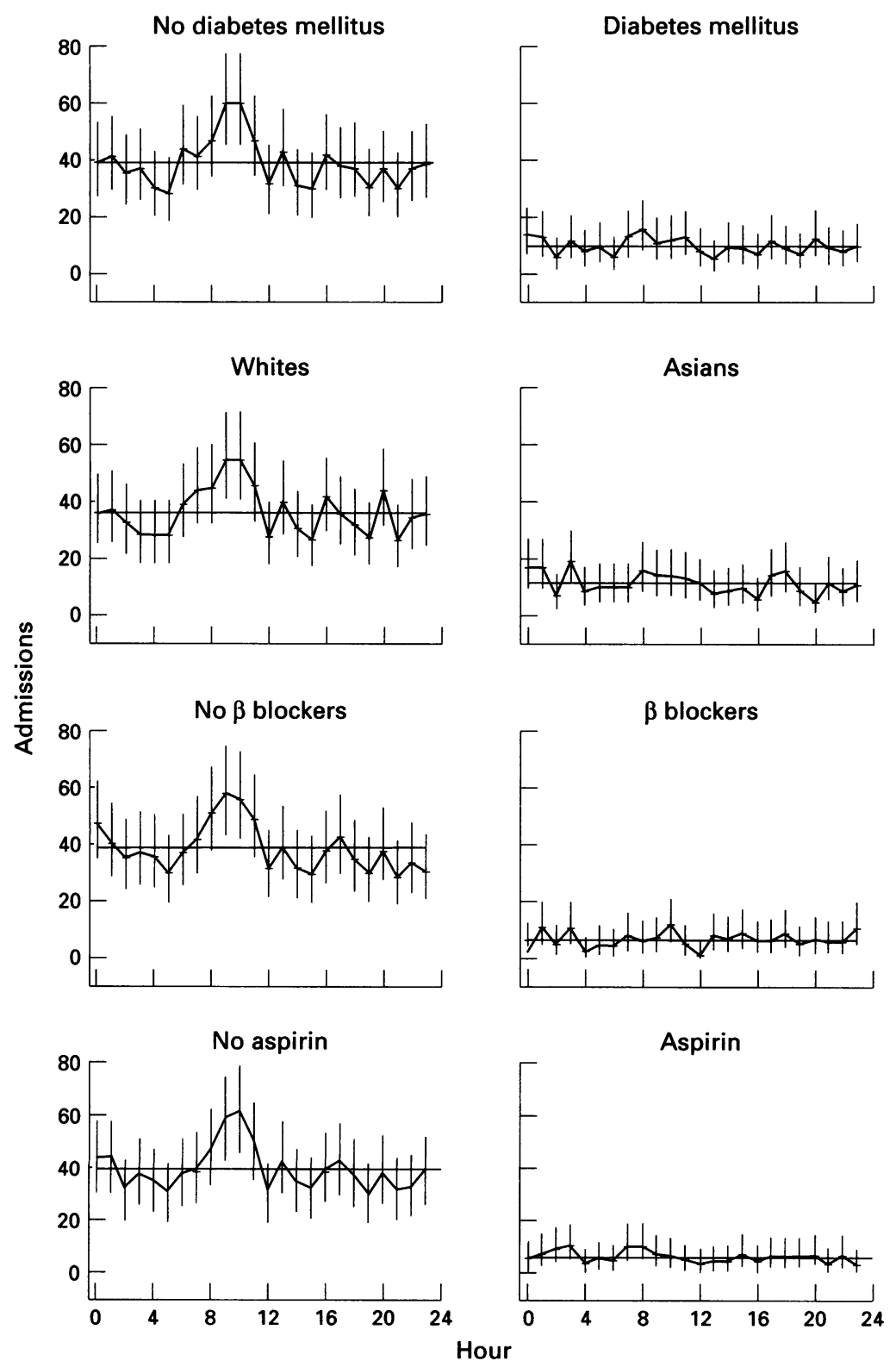

Figure 2 Admission rates by hour of day according to subgroups. Error bars are $95 \%$ confidence intervals. subgroups in whom the rhythms are attenuated or absent, and to determine a link between the subgroups to provide further information about the mechanisms of the rhythms and, by inference, the mechanisms responsible for initiating the process of infarction.

\section{Patients and methods}

STUDY POPULATION

The study population comprised 1225 consecutive patients with acute myocardial infarction admitted to the coronary care unit of Newham General Hospital in London from 1 January 1988 to 31 December 1994. The diagnosis of acute myocardial infarction was based on any two of the following three criteria: (a) cardiac chest pain lasting at least 30 minutes; (b) electrocardiographic changes of myocardial infarction with $\geqslant 0.1 \mathrm{mV} \mathrm{ST}$ elevation in at least one standard lead or $\geqslant 0.2 \mathrm{mV}$ ST elevation in two or more contiguous chest leads; (c) a diagnostic rise in creatine kinase to $\geqslant 400 \mathrm{IU} / 1$ (upper limit of reference range $200 \mathrm{IU} / \mathrm{l}$ ).

\section{DATA COLLECTION}

Baseline data, including the date and time of onset of chest pain, details of treatment on admission, diabetic status, racial group, and smoking habit were collected prospectively at the time of admission by a clinician and entered on a customised database. Racial group was recorded in all patients by direct inquiry; South Asian was defined as Indian, Pakistani or Bangladeshi. A diagnosis of diabetes was recorded if the patient required insulin, oral hypoglycaemic drugs, or dietary sugar restriction. Smoking habit was classified into non-smokers (those who had never smoked or stopped prior to admission) or current smokers.

\section{DATA ANALYSIS}

Circadian rhythm was calculated according to the number of patients per hour admitted each day. Admission rates were also calculated according to the day of the week (weekly rhythm) and month of year (seasonal rhythm). Data were analysed for variations within the whole group and according to sex, racial group (excluding the 25 patients of Afro-Caribbean origin), diabetic status, smoking habit, history of myocardial infarction, and drugs being taken on admission (aspirin, $\beta$ blockers). Tests of heterogeneity were applied. ${ }^{18}$ Confidence intervals (95\% CIs) were derived from tabulations of the Poisson distribution.

Results

The average (SD) age of the 1225 patients was $62 \cdot 1(11.9)$ years. Other baseline characteristics are summarised in table 1 .

\section{CIRCADIAN RHYTHM}

The time of onset of symptoms, available in 1182 patients (97\%), showed significant circadian variation with a morning peak centred around 0900 against an otherwise 


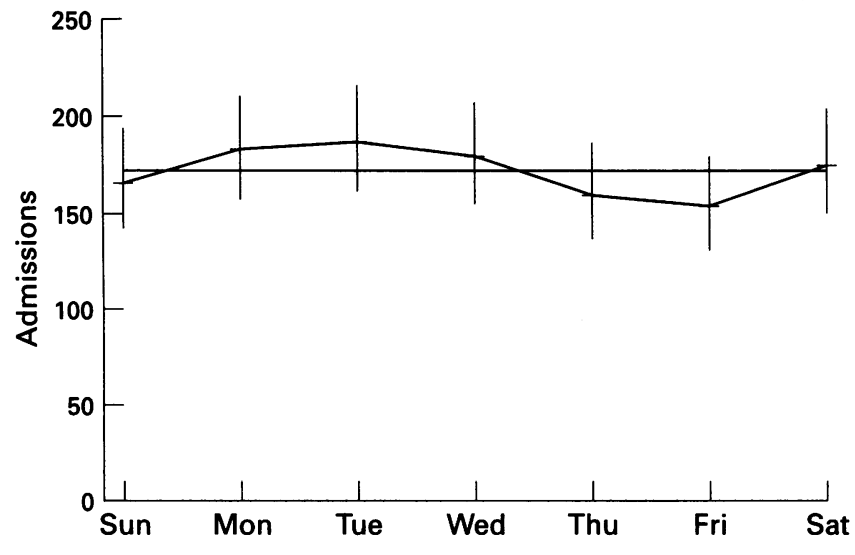

Figure 3 Admission rates by day of the week for 1225 patients. Test for heterogeneity: $\chi^{2}=5 \cdot 3$ on 6 degrees of freedom, $P=0.51$. Error bars are $95 \%$ confidence intervals.

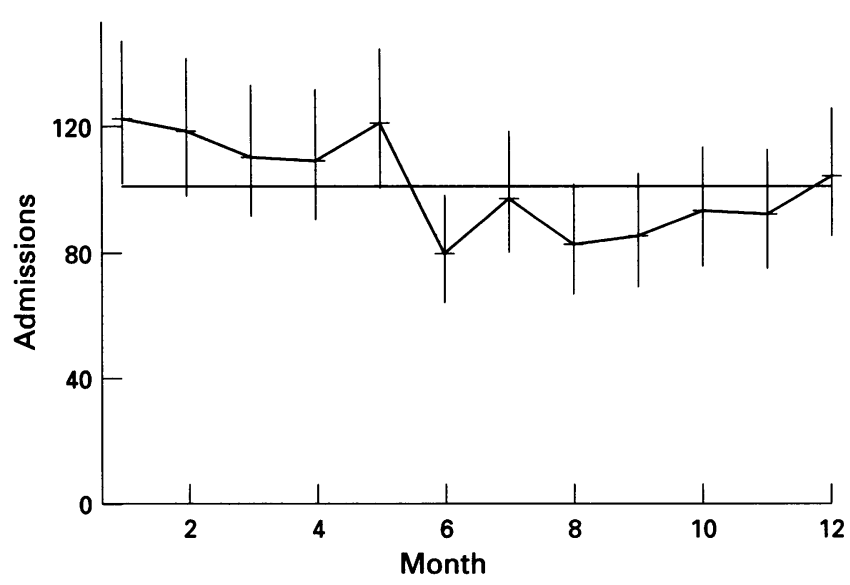

Figure 4 Admission rates by month of year for 1225 patients. Test for heterogeneity: $\chi^{2}=25 \cdot 2$ on 11 degrees of freedom, $P=0.009$. Error bars are $95 \%$ confidence intervals.
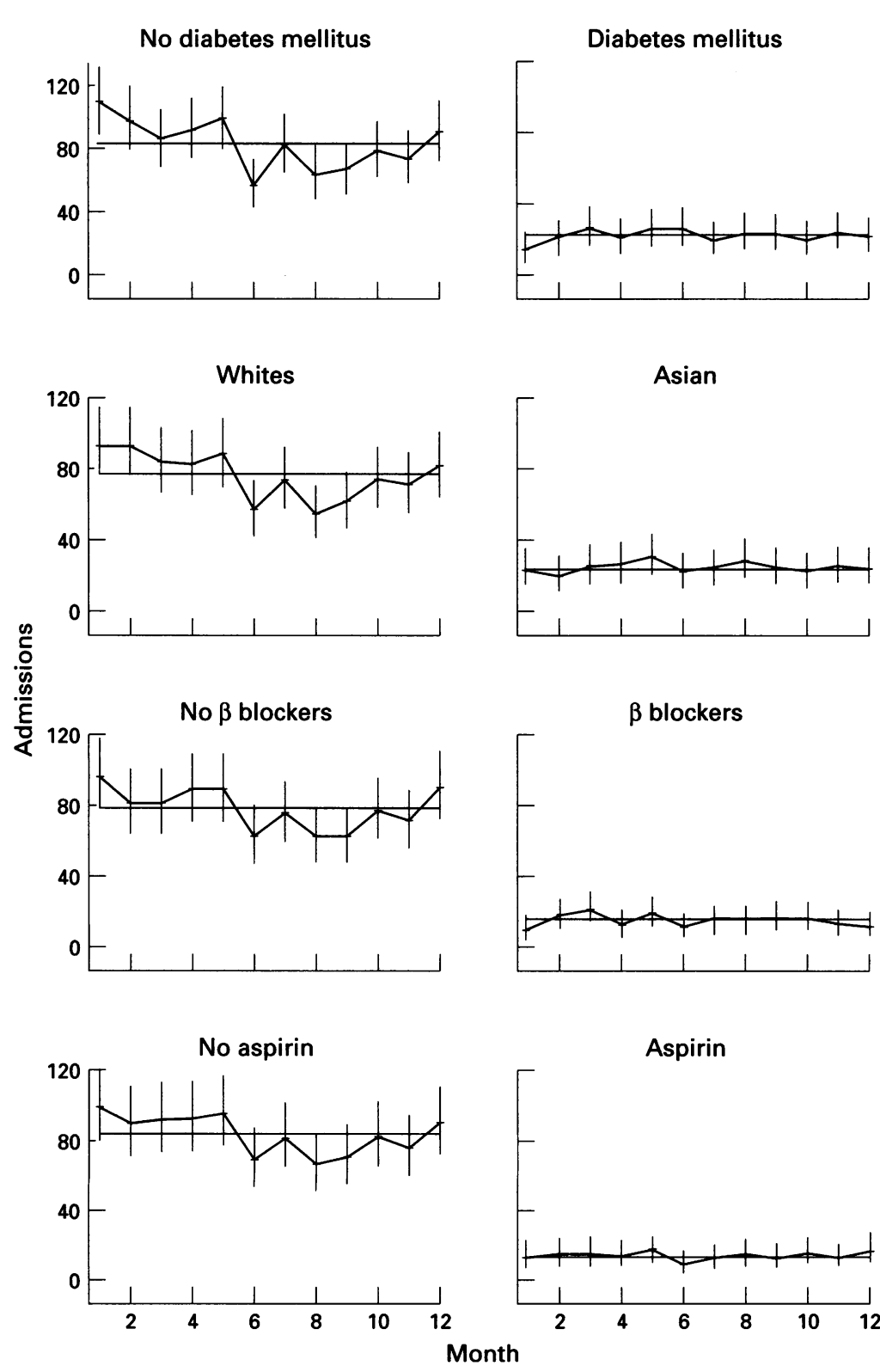

Figure 5 Admission rates by month of year according to subgroups. Error bars are $95 \%$ confidence intervals. fairly constant background rate $(P=0.006)$ (fig 1).

\section{SUBGROUP ANALYSIS}

In contrast to the group as a whole, the circadian pattern of symptom onset was either lost or attenuated in patients who were diabetic, South Asian, or taking $\beta$ blockers or aspirin on admission, females, smokers or patients with a history of previous myocardial infarction (fig 2, table 2).

\section{WEEKLY RHYTHM}

Although there was a trend towards higher admission rates at the beginning of the week this was not significant $(P=0.51)$; similarly, no significant variation could be demonstrated within subgroups (fig 3 ).

\section{SEASONAL RHYTHM}

Admission rates for the entire cohort were significantly higher during the winter than the summer months ( $P=0.009$ ) (fig 4).

\section{SUBGROUP ANALYSIS}

In patients who were diabetic, South Asian, taking $\beta$ blockers or aspirin on admission, and smokers, trends were strikingly similar to those of circadian variation, in that no seasonal variation could be demonstrated (fig 5, table 2).

\section{Discussion}

The circadian and seasonal rhythms of acute myocardial infarction are well documented. Previous investigators have reported an absence of circadian rhythm in diabetics and patients taking $\beta$ blockers, an observation confirmed by the present study. ${ }^{461617}$ We have extended this observation by demonstrating absence of circadian rhythm not only in diabetics and patients taking $\beta$ blockers but also in South Asians and patients taking aspirin. Moreover, we have shown for the first time that the seasonal variability of acute myocardial infarction is absent in almost identical subgroups, suggesting that common mechanisms may be involved in driving these rhythms. 
Table 2 Subgroup analyses of admission rates by hour of day and month of year. Results are derived from tests for heterogeneity

\begin{tabular}{|c|c|c|c|c|c|c|}
\hline & \multicolumn{3}{|c|}{ Admission by hour of day } & \multicolumn{3}{|c|}{ Admission by month of year } \\
\hline & Number & $\chi^{2}$ & $P$ & Number & $\chi^{2}$ & $P$ \\
\hline \multicolumn{7}{|l|}{ Sex } \\
\hline Men & 873 & $36 \cdot 7$ & 0.03 & 900 & $21 \cdot 2$ & 0.03 \\
\hline Women & 309 & $26 \cdot 6$ & $0 \cdot 20$ & 325 & $18 \cdot 3$ & 0.07 \\
\hline \multicolumn{7}{|l|}{ Racial group } \\
\hline White & 881 & $42 \cdot 6$ & 0.005 & 917 & 28.9 & 0.002 \\
\hline South Asian & 276 & $28 \cdot 8$ & $0 \cdot 15$ & 283 & $4 \cdot 0$ & 0.97 \\
\hline \multicolumn{7}{|l|}{ Diabetes } \\
\hline Non-diabetic & 939 & $39 \cdot 8$ & 0.02 & 972 & $36 \cdot 5$ & 0.0001 \\
\hline Diabetic & 241 & $19 \cdot 4$ & $0 \cdot 68$ & 250 & $6 \cdot 5$ & 0.84 \\
\hline \multicolumn{7}{|l|}{ Smoking status } \\
\hline Non-smokers & 548 & $47 \cdot 6$ & 0.001 & 566 & $18 \cdot 4$ & 0.07 \\
\hline Smokers & 616 & $20 \cdot 4$ & 0.56 & 635 & $16 \cdot 0$ & $0 \cdot 14$ \\
\hline \multicolumn{7}{|l|}{ Infarct history } \\
\hline First infarct & 881 & $43 \cdot 3$ & 0.004 & 914 & $22 \cdot 3$ & 0.02 \\
\hline Previous infarct & 301 & $29 \cdot 5$ & $0 \cdot 13$ & 309 & $18 \cdot 9$ & 0.06 \\
\hline \multicolumn{7}{|l|}{ Admission drugs } \\
\hline No $\beta$ blockers & 931 & $35 \cdot 2$ & 0.04 & 959 & $22 \cdot 1$ & 0.02 \\
\hline$\beta$ blockers & 159 & $25 \cdot 6$ & $0 \cdot 27$ & 166 & $10 \cdot 2$ & 0.51 \\
\hline No aspirin & 954 & $39 \cdot 7$ & 0.01 & 983 & $18 \cdot 2$ & 0.08 \\
\hline Aspirin & 140 & $19 \cdot 6$ & $0 \cdot 61$ & 146 & $5 \cdot 75$ & $0 \cdot 89$ \\
\hline
\end{tabular}

The hour of pain onset and the month of admission were available in 1182 and 1225 patients, respectively. blockers. It may also account, at least in part, for the absence of these rhythms in diabetic patients, a group in whom autonomic dysfunction is common and associated with impairment of normal circadian patterns of sympathovagal activity. ${ }^{24-26}$ Over $40 \%$ of the South Asians included in the present study were diabetic (compared with $14 \%$ of the white patients) and this is probably sufficient to explain the absence of circadian and seasonal variability in this ethnic group, although whether the insulin resistance syndrome, which appears to predispose them to coronary artery disease, itself affects autonomic function is not known. Our data also showed severe attenuation of circadian rhythm in patients with previous myocardial infarction, a group in whom ischaemic and sympathovagal rhythms are diminished or lost altogether in the early post-infarction period with continuing impairment for up to 12 months. ${ }^{2027-29}$ Add to this the fact that $26 \%$ of these patients were taking $\beta$ blockers at the time of admission (compared with $11 \%$ of patients with first infarcts), the attenuation of circadian variability might well be related to deranged autonomic function.

Thus, across a range of subgroups it is possible to associate pharmacological or pathological derangement of autonomic function with attenuation of circadian and seasonal rhythms of myocardial infarction. If this association is correct, it lends weight to the hypothesis that both rhythms are driven by the autonomic nervous system, increased sympathetic activity in the morning and the winter, predisposing to plaque events at these times. The risk attributable to heightened sympathetic activity may not be limited to its haemodynamic effects. Thus, sympathetic stimulation may enhance platelet aggregation through increases in $\beta$ thromboglobulin and platelet factor $4,{ }^{30}$ with cyclical variations in plasminogen activator inhibitor and other haemostatic variables making a further potential contribution to the increased risk of myocardial infarction in the mornings and the winter. ${ }^{31}{ }^{32}$ Our finding that aspirin therapy effectively abolished both the circadian and seasonal rhythms of infarction would, therefore, be consistent with its antiplatelet effects providing protection against coronary thrombosis at these times of heightened risk.

Not all the findings in the present study are readily explained in terms of altered autonomic or haemostatic function. The absence of circadian variability in women is hard to account for although it has been commented upon by other investigators. ${ }^{4}$ Similarly, there is no clear explanation for the absence of circadian and seasonal variability in smokers although it is possible that nicotine induced sympathetic stimulation and the prothrombotic effects of smoking (mediated largely by increased circulating fibrinogen concentrations) might together be sufficient to obscure these rhythms. ${ }^{33}$ It is also possible that in some of the smaller subgroup analyses the rhythms were obscured by background noise, although the striking parallels between subgroups in by provoking plaque events through rises blood pressure. Certainly, modification of sympathetic activity is likely to account for the observation that neither of these rhythms could be demonstrated in patients taking $\beta$ 
whom both circadian and seasonal rhythms were absent makes this unlikely.

Previous authors have reported an increased risk of myocardial infarction on Mondays and have speculated that this too reflects heightened sympathetic activity on the first day back to work. ${ }^{12-15} \mathrm{We}$ were unable to confirm this, although there was a tendency for myocardial infarction to occur more commonly in the first part of the week. It should be recognised, however, that $50 \%$ of the patients included in our study were over the retirement age (60 for women, 65 for men) and although the employment status of the remainder was unknown it was likely to be low in this socially deprived part of east London. The increased risk of myocardial infarction on Mondays reported by previous investigators appeared to be confined to the working population ${ }^{15}$ and the absence of a weekly rhythm in the present study was, therefore, not surprising.

In conclusion, this study has demonstrated attenuation or absence of both circadian and seasonal rhythms of acute myocardial infarction in almost identical subgroups. This suggests that common mechanisms may be involved in driving these rhythms, the autonomic nervous system being a likely candidate. Thus, the rhythms were absent in patients taking $\beta$ blockers and in patients in whom derangement of autonomic function commonly occurs. The absence of circadian and seasonal rhythms in diabetics, South Asians, smokers and patients with previous myocardial infarction suggests differences in the mechanisms of infarction in these high risk subgroups which may have important implications for prophylactic care.

1 Thompson DR, Sutton TW, Jowett NI, Pohl JE. Circadian variation in the frequency of onset of chest pain in acute myocardial infarction. Br Heart $\mathcal{f} 1991 ; 65: 177-8$.

2 Kono T, Morita H, Nishina T, Fujita M, Hirota Y, Kawamura $\mathrm{K}$, et al. Circadian variations of onset of acute myocardial infarction and efficacy of thrombolytic thermyocardial infarction and efficacy of

3 Goldberg RJ, Brady P, Muller JE, Chen Z, de Groot M, Zonneveld P, et al. Time of onset of symptoms of acute

4 Hjalmarson A, Gilpin EA, Nicod P, Dittrich H, Henning $\mathrm{H}$, Engler R, et al. Differing circadian patterns of symptom onset in subgroups of patients with acute myocardial infarction. Circulation 1989;80:267-75.

5 Thompson DR, Blandford RL, Sutton TW, Marchant PR. Time of onset of chest pain in acute myocardial infarction. Int $\mathcal{F}$ Cardiol 1985;7:139-46.

6 Muller JE, Stone PE, Turi ZG, Rutherford JD, Czeisler $\mathrm{CA}$, Parker C, et al. Circadian variation in the frequency of onset of acute myocardial infarction. $N$ Engl $f$ Med 1985;313:1315-22.

7 Willich SN, Levy D, Rocco MB, Tofler GH, Stone PH, Muller JE. Circadian variation in the incidence of sudden cardiac death in the Framingham Heart Study population. Am $\mathcal{F}$ Cardiol 1987;60:801-6.

8 Taylor CR, Hodge EM, White DA. Circadian rhythms of angina: similarity to circadian rhythms of myocardial infarction, ischaemic ST segment depression, and sudden cardiac death. The Amlodipine Angina Study Group. Am Heart 7 1989;118:1098-9.

9 Rocco MB, Barry J, Campbell S, Nabel E, Cook EF, Goldman L, et al. Circadian variation of transient myocardial ischaemia in patients with coronary artery myocardial ischaemia in patients with

10 Mulcahy D, Keegan J, Crean P, Quyyumi A, Shapiro L,
Wright C, et al. Silent myocardial ischaemia in chronic table angina: a study of its frequency and characteristics in 150 patients. Br Heart 7 1988;60:417-23.

11 Marchant B, Ranjadayalan K, Stevenson R, Wilkinson P, Timmis AD. Circadian and seasonal factors in the pathogenesis of acute myocardial infarction: the influence of environmental temperature. Br Heart $\mathcal{f}$ 1993;69:385-7.

12 Thompson DR, Pohl JE, Sutton TW. Acute myocardial infarction and day of the week. Am $\mathcal{F}$ Cardiol 1992;69: 266-7.

13 Gnecchi-Ruscone T, Piccalga E, Guzzetti S, Contini M, Montano $N$, Nicolis $E$, on behalf of GISSI-2 Investigators. Mornings and Monday: critical periods for the onset of acute myocardial infarction. Eur Heart $\mathcal{f}$ 1994;15:882-7.

14 Willich SN, Linderer T, Wegscheider $K$, Leizorovicz A, Alamercery I, Schroder R. Increased morning incidence of myocardial infarction in the ISAM study: absence with prior $\beta$-adrenergic blockade. Circulation 1989;80:853-8. ilich SN, Lowel H, Lewis, Hormann A, Arntz HR, Keil Increased Monday risk in the working population. Circulation 1994;90:87-3.

16 Tanaka $T$, Fujita $M$, Fudo $T$, Tamaki S, Nohara $R$, Sasayama S. Modification of the circadian variation of symptom onset of acute myocardial infarction in diabetes symptom onset of acute myocardial infarcti
mellitus. Coron Artery Dis 1995;6:241-4.

17 Fava S, Azzopardi J, Muscat HA, Fenech FF. Absence of circadian variation in the onset of acute myocardial infarction in diabetic subjects. Br Heart $\mathcal{F} 1995 ; 74: 370-2$.

18 Breslow NE, Day NE. Statistical methods in cancer research. Vol II. The design and analysis of cohort studies. Oxford: Oxford University Press, 1987:82-118.

19 Deedwania PC, Nelson JR. Pathophysiology of silent myocardial ischemia during daily life. Hemodynamic evaluation by simultaneous electrocardiographic and blood pressure monitoring. Circulation 1990;82:1296-304.

20 Marchant B, Stevenson R, Vaishnav S, Wilkinson P, Ranjadayalan K, Timmis AD. Influence of the autonomic nervous system on circadian patterns of myocardial ischaemia: comparison of stable angina with the early post-infarction period. Br Heart $\mathcal{f}$ 1994;71:329-33.

21 Turton MB, Deegan T. Circadian variations in catecholamine, cortisol, and immunoreactive insulin concencholamine, cortisol, and immunoreactive insulin concen389-97.

22 Marchant B, Donaldson G, Mridha K, Scarborough M, Timmis AD. Mechanisms of cold intolerance in patients with angina. F Am Coll Cardiol 1994;23:630-6.

23 Richardson P, Davies M, Born G. Influences of plaque configuration and stress distribution on fissuring of coronary atherosclerotic plaques. Lancet 1989;ii:941-4.

24 Zarich S, Waxman S, Freeman RT, Mittleman M, Hegarty $P$, Nesto RW. Effect of autonomic nervous system dysfunction on the circadian pattern of myocardial ischemia in diabetes mellitus. $7 \mathrm{Am}$ Coll Cardiol 1994;24:956-62.

25 Bernardi L, Ricordi L, Lazzari P, Solda P, Calciati A, Ferrari MR, et al. Impaired circadian modulation of sympathovagal activity in diabetes. A possible explanation for altered temporal onset of cardiovascular disease. Circulation 1992;86:1443-52.

26 Marchant B, Umachandan V, Stevenson R, Kopelman P, Timmis AD. Silent myocardial ischemia: Role of subclinical neuropathy in patients with and without diabetes. $f$ Am Coll Cardiol 1993;22:1433-7.

27 Lombardi F, Sandrone G, Perpruner S, Sala R, Garimoldi $\mathrm{M}$, Cerutti S, et al. Heart rate variability as an index of sympathovagal interaction after acute myocardial infarction. Am 7 Cardiol 1987;60:1239-45.

28 Vaishnav S, Stevenson R, Marchant B, Ranjadayalan K Timmis AD. The relation between heart rate variability early after acute myocardial infarction and long-term mortality. Am $\mathcal{F}$ Cardiol 1994;73:653-7.

29 Bigger JT, Fleiss JL, Rolnitzky LM, Steinman RC Schneider WJ. Time course of recovery of heart period variability after myocardial infarction. $\mathcal{F} \mathrm{Am}$ Coll Cardio 1991;18:1643-9.

30 Kawahara J, Sano H, Fukuzaki H, Saito K, Hirouchi H. Acute effects of exposure to cold on blood pressure, platelet function and sympathetic nervous activity in humans. Am $\mathcal{F}$ Hypertens 1989;2:724-6.

31 Andreotti F, Davies GJ, Hackett DR, Khan MI, De Bart AC, Aber VR, et al. Major circadian fluctuations in fibrinolytic factors and possible relevance to time of onset of myocardial infarction, sudden cardiac death and stroke. Am $f$ Cardiol 1988;62:635-7.

32 Bridges AB, McLaren M, Scott NA, Pringle TH, McNeil GP, Belch JJ. Circadian variation of tissue plasminogen activator and its inhibitor, von Willebrand factor antigen, activator and its inhibitor, von Willebrand factor antigen, and prostacyclin stimulating factor in men

33 Benowitz NL. Pharmacologic aspects of cigarette smoking and nicotine addiction. N Engl F Med 1988;319:1318-30 